\title{
El impacto de la Doctrina “de la Seguridad Nacional” en la Argentina durante la Guerra Fría (1955-1983) *
}

The impact of the "National Security" Doctrine in Argentina during the Cold War (1955-1983)

\author{
María Florencia Osuna* \\ Esteban Pontoriero*
}

\begin{abstract}
Resumen: Este artículo analiza el impacto de las dimensiones de la "Seguridad" y el "Desarrollo" de la Doctrina "de la Seguridad Nacional" en Argentina, en el periodo 19551983. En este sentido, por un lado, estudia el proceso de incorporación de la seguridad interna al campo de la defensa nacional en clave antisubversiva. Por otro lado, da cuenta de la dimensión social, económica y cultural de la DSN ligada con otro tipo de intervención que buscaba el "desarrollo" de los países periféricos para evitar estallidos revolucionarios.
\end{abstract}

Palabras clave (Thesaurus de la UNESCO): Argentina; Doctrina; Seguridad; Historia Contemporánea; Fuerzas Armadas; Desarrollo Económico y Social

\begin{abstract}
This article analyzes the impact of the dimensions of "Security" and "Development" of the "National Security" Doctrine in Argentina, in the period 1955-1983. In this sense, on the one hand, it studies the process of incorporating internal security into the field of national defense in an antisubversive way. On the other hand, it gives an account of the social, economic and cultural dimension of the "National Security" Doctrine linked to another type of intervention that sought the "development" of the peripheral countries to avoid revolutionary outbreaks.
\end{abstract}

Keywords (UNESCO Thesaurus): Argentina; Doctrine; Security; Contemporany History; Armed Forces; Economic and Social Development

Recibido: 24 octubre 2018 Aceptado: 2 diciembre 2018

\footnotetext{
* Esta investigación se realizó con financiamiento del Consejo Nacional de Investigaciones Científicas y Técnicas en el marco de nuestras investigaciones doctorales sobre la incorporación de la seguridad interna a la esfera de la defensa en clave contrainsurgente en la Argentina entre 1955 y 1976, y acerca de las políticas sociales de las últimas dictaduras argentinas (19661983). Las tesis fueron presentadas en el Instituto de Altos Estudios Sociales de la Universidad Nacional de San Martín y en la Facultad de Filosofía y Letras de la Universidad de Buenos Aires respectivamente.

* Argentina. Coautora. Becaria posdoctoral del CONICET-Universidad Nacional de General Sarmiento, profesora en las Universidades Nacionales de General Sarmiento y de La Plata. E-mail: florenciaosuna@gmail.com

* Argentino. Coautor. Becario posdoctoral del CONICET-Universidad Nacional de General San Martín, profesor en la Universidad Nacional de Tres de Febrero. E-Mail: estebanpontoriero@hotmail.com.
} 


\section{Introducción}

El período histórico iniciado con el golpe de Estado del 16 de septiembre de 1955 y finalizado con el retorno democrático de 1983 se caracterizó por la inestabilidad política, económica y social. Entre los principales motivos, se destacaban la enorme dificultad del sistema político argentino y sus protagonistas para procesar el conflicto político-social vinculado con la contradicción entre el peronismo y el antiperonismo. También se relacionaba con el surgimiento en los años sesenta de una gran cantidad de agrupamientos contestatarios que expresaron una radicalización hacía la izquierda de un conjunto de actores políticos, generacionales, sindicales y culturales, entre otros. Por su parte, otro elemento distintivo fue la alternancia de gobiernos constitucionales y de facto, que por diversos medios buscaron erradicar al peronismo de la escena local, recurriendo principalmente a la proscripción electoral y a la represión de las protestas, huelgas y otras acciones de resistencia. Asimismo, durante los gobiernos constitucionales de la década del setenta se registró el aumento de los hechos de violencia política por parte de las organizaciones político-militares, los grupos paraestatales y la represión interna legal y clandestina, en medio de una creciente agudización de la conflictividad social. Este proceso se constituyó en el marco previo al golpe militar de marzo de 1976, el inicio del autodenominado "Proceso de Reorganización Nacional" (1976-1983) y la implementación del terrorismo de Estado en todo el país'

Este trabajo se inserta en un campo de estudios que abordan la historia de la Guerra Fría en América Latina desde el punto de vista cultural, especialmente en lo referido a las relaciones de los países de esa región con los Estados Unidos. En efecto, como señalan Benedetta Calandra y Marina Franco se trata de explorar "una densa red de actores, prácticas y estrategias comunicativas que en la esfera de la diplomacia cultural y en el marco cronológico de la Guerra Fría contribuyeron de manera esencial a la exportación del American $W$ ay of Life en el subcontinente, incluyendo las múltiples formas de su recepción y reelaboración a nivel local"2. En vinculación con la problemática de este artículo, esa definición se emparenta con el interés por estudiar la circulación de las nociones asociadas a la doctrina "de la Seguridad Nacional" (DSN) entre los dirigentes políticos y las autoridades militares de nuestro país durante los años sesenta y setenta.

La presente contribución se propone avanzar sobre el terreno de lo que puede denominarse como una historia cultural de la llamada "guerra contra la subversión". En la primera sección se analiza el proceso de incorporación de la seguridad interna al campo de la defensa nacional en clave antisubversiva. En relación con esto, se presta particular atención a las características de las doctrinas antisubversivas francesa y estadounidense, priorizando esta última y la conexión que establece entre la seguridad y el desarrollo en la "lucha contra el comunismo". Asimismo, se da cuenta de las vías por las que el Ejército argentino incorporó ambas escuelas de pensamiento contrainsurgente. En la segunda sección, se atiende a la trama transnacional de ideas, actores e instituciones vinculada con el desarrollismo social, económico y cultural que, en la década del cincuenta, comenzó a intervenir en los países periféricos para evitar la proliferación de prácticas políticas contestatarias. A su vez, se analiza el impacto y apropiación de este entramado en Argentina, y su traducción en discursos oficiales y políticas públicas.

Al igual que en otros trabajos realizados en esa línea, aquí también se escogió el análisis de las esferas político-civil y militar en vistas de identificar puntos de contacto alrededor de una serie de tópicos vinculados a la DSN proveniente de EE.UU³.

\footnotetext{
1 César Tcach, "Golpes, proscripciones y partidos políticos", Daniel James (ed.), Nueva historia argentina: Violencia, proscripción y autoritarismo 1955-1976, Buenos Aires, Sudamericana, 2003, 17-61; Marcos Novaro y V ic en te Palermo, La dictadura militar 1976-1983: del golpe de Estado a la restauración democrática, Buenos Aires, Paidós, 2006.

2 Benedetta Calandra y Marina Franco, "Desafíos y límites para una nueva Mirada de las relaciones interamericanas", Benedetta Calandra y Marina Franco (eds.), La Guerra fría cultural en América Latina, Buenos Aires, Biblos, 2012, 11.

${ }_{3}^{3}$ Florencia Osuna, La intervención social del Estado. El Ministerio de Bienestar Social entre dos dictaduras (Argentina, 1966-1983, Rosario, Prohistoria, 2017; Esteban Pontoriero, “La seguridad interna como 'teatro de guerra': estado de excepción y contrainsurgencia
} 


\section{Una doctrina militar para la seguridad interna}

Durante el período 1955-1983, para el actor militar el control del orden interno pasó a constituir una preocupación política central. En efecto, con posterioridad a 1955 se planteó la necesidad de readaptar la doctrina militar al contexto de la Guerra Fría. En este sentido, el escenario eventual de una guerra atómica entre las grandes potencias determinó la búsqueda de un rol profesional más acorde a los recursos humanos y materiales disponibles, por lo que la represión y el rol de guardián de las fronteras internas se presentaron como un par de buenas opciones ${ }^{4}$.

Derivado de esto, a fines de los años cincuenta el arma terrestre adoptó los principios de la Doctrina "de la Guerra Revolucionaria" (DGR), desarrollados por el Ejército francés, aunque este vínculo también se vio impulsado por razones institucionales. Según un grupo de especialistas, el Ejército incorporó la DGR en 1957, en consonancia con la fundación de la primera misión de asesores militares de ese país en la Escuela Superior de Guerra local. En relación con esto, los oficiales extranjeros se abocaron a la tarea de enseñar la teoría y los métodos de la "guerra revolucionaria", así como los medios para enfrentarla, tomando como modelos los casos de las guerras de Indochina (1946-1954) y Argelia (1954-1962). Para cumplir con esa labor, se impartieron cursos en instituciones castrenses y se llevaron adelante ejercicios de guerra en diferentes puntos del país ${ }^{5}$ Paralelamente, la difusión de las nuevas ideas se llevó adelante por diferentes medios como, por ejemplo, las estadías y viajes formativos de oficiales argentinos en las academias militares galas, la publicación de artículos en revistas castrenses, la edición de bibliografía y la realización de cursos y conferencias) ${ }^{6}$.

En primer lugar, la DGR se componía de una teoría de los conflictos bélicos, tanto internos como externos. En relación con esto, se afirmaba que el mundo surgido luego del final de la Segunda Guerra Mundial (1939-1945) se hallaba inmerso en un estado de guerra permanente, careciendo de una declaración formal, entre dos bloques geopolíticos antagónicos: el occidental, encabezado por EE.UU. y definido como "capitalista, democrático y cristiano", y el comunista, dirigido por la Unión Soviética y señalado como "marxista, totalitario y ateo". En este sentido, toda manifestación de conflicto interno dentro de los países del primer bloque debía encuadrarse en este marco de análisis. Por lo tanto, las protestas, huelgas, movilizaciones y/o reclamos debían interpretarse como fases de la guerra permanente, multiforme e integral el bloque comunista llevaba adelante en contra de EE.UU. y sus aliados.

El concepto de "guerra revolucionaria" concentraba el saber desarrollado por los militares franceses, afirmando que de esa forma el "comunismo" buscaba la victoria en los países del bloque occidental. En efecto, se indicaba que este fenómeno bélico se distinguía por llevarse adelante dentro de las fronteras nacionales, sin poseer una declaración formal, a través de diversas esferas y ejecutándose por una infinidad de vías, a saber, políticas, militares, económicas o psicológicas. En consecuencia, la "guerra revolucionaria" tenía por objetivo lograr la subversión del poder político existente para imponer

en la Argentina (1955-1976)", Tesis de Doctorado, Instituto de Altos Estudios Sociales, Universidad Nacional de San Martín, 2017.

${ }^{4}$ Ernesto López, Seguridad Nacional y sedición militar, Buenos Aires, Legasa, 1987, 130-145; Mario Ranalletti, "Una aproximación a los fundamentos del terrorismo de Estado en Argentina: la recepción de la noción de 'guerra revolucionaria' en el ámbito castrense local (1954-1962)", Anuario del Centro de Estudios Históricos "Prof. Carlos S. A. Segreti”, 11, 2011, 271-272.

${ }_{5}^{5}$ Un ejercicio o juego de guerra es una actividad práctica dentro de la formación castrense basada en la simulación de una situación de combate. En este sentido, mediante un complejo sistema de instrucciones y órdenes asignadas por los docentes se busca reproducir un escenario de enfrentamiento bélico en el que un grupo de alumnos representa a las fuerzas propias y otro a las enemigas. Ver Oscar Kaplan, Diccionario Militar, Buenos Aires, Biblioteca del Suboficial, 1944, 377.

6 Samuel Amaral, "Guerra revolucionaria: de Argelia a la Argentina, 1957-1962", Investigaciones y Ensayos, 48, 1998, 182-183; Daniel Mazzei, "La misión militar francesa en la Escuela Superior de Guerra y los orígenes de la Guerra Sucia, 1957-1961”, Revista de Ciencias Sociales, 13,2002, 106; Marie-Monique Robin, Escuadrones de la muerte: la escuela francesa, Buenos Aires, Sudamericana, 2005, 231. Los párrafos siguientes dedicados a la DGR son tributarios de esta bibliografía. 
un nuevo régimen aliado con el bloque dirigido por la Unión Soviética, avanzando en la implantación del "comunismo".

En segundo lugar, junto a este marco para la comprensión de los conflictos de la Guerra Fría, la DGR contenía una serie de técnicas de combate, comenzando por la división del territorio en zonas de defensa militares (cuadriculación) y la subordinación de las fuerzas de seguridad al mando de las FF.AA. En relación con esto, el objetivo principal era el control de la población, aspecto que se vinculaba con la necesidad de combatir contra un "enemigo interno" que se escondía en ella. Por ese motivo, las medidas prescriptas se dirigían a lograr el mantenimiento de la seguridad.

A su vez, se prescribía un conjunto de técnicas de "acción psicológica" cuyo objetivo era fortalecer el espíritu de combate en las fuerzas militares propias y la población aliada, al tiempo que se recomendaba una serie de operaciones de "guerra psicológica" para debilitar la moral de las tropas enemigas y sus aliados. Es importante aclarar que junto a esto existía un grupo de prácticas ilegales y criminales que formaban parte de la realidad de la "guerra antisubversiva" como, por ejemplo, los espacios de detención clandestinos, la metodología del secuestro y la tortura para la obtención de información y la muerte y posterior desaparición de los cadáveres de las víctimas.

Desde 1962, la formación de la doctrina contrainsurgente del Ejército inició un proceso de reforma destacado: DSN estadounidense desplazó la influencia francesa de su lugar de privilegio, habilitándose el camino para una simbiosis entre ambas 7 . Entre los motivos que explican este cambio sustancial puede mencionarse que el grupo castrense que alcanzó el control del Ejército en ese momento, pertenecientes a llamada la facción "azul", tenían contactos muy estrechos con la Embajada estadounidense y sus FF.AA. En este sentido, los generales Juan Carlos Onganía, Alejandro Lanusse y Julio Alsogaray fueron los principales impulsores de la DSN. Sin embargo, el ocaso de la influencia francesa también se relacionaba con otras causas: por ejemplo, la crisis del Ejército galo caracterizada por la indisciplina, desobediencia y ruptura de la cadena de mandos ocurrida entre 1961 y 1962 durante las etapas finales de la Guerra de Argelia. Efectivamente, la oposición violenta y encarnizada de una parte de los oficiales y colonos argelino-franceses frente a los planes de descolonización del presidente Charles De Gaulle (1959-1969) llevó a las autoridades políticas galas a reemplazar la primacía de la doctrina contrainsurgente por una basada en la guerra nuclear. Asimismo, luego de la revolución y posterior incorporación de Cuba al bloque socialista -en 1959 y 1961, respectivamente-, las FF.AA. estadounidenses modificaron la doctrina de la seguridad hemisférica por una centrada a la represión interna. En efecto, una vez que se dejó de lado la hipótesis de una guerra abierta contra la Unión Soviética, la preocupación central de los especialistas de El Pentágono se concentró en el control y la destrucción de los movimientos revolucionarios por parte de las fuerzas militares locales. Por lo tanto, a diferencia de lo ocurrido con la DGR, la adopción de la DSN por parte del Ejército argentino formaba parte de un proceso que abarcaba a toda la región latinoamericana ${ }^{8}$.

$\mathrm{Al}$ igual que en el caso francés, el enfoque antisubversivo estadounidense se desarrolló al calor de los procesos de descolonización de los años cincuenta y sesenta, cuando la Unión Soviética y EE.UU. comenzaron la competencia por el predominio geopolítico de América Latina, Asia y África. Asimismo, el "Tercer Mundo" empezó a definirse como un área que tenía problemas similares, planteando así la necesidad de adoptar una política común. En este sentido, los lineamientos básicos fueron diseñados durante la presidencia de John Fitzgerald Kennedy (1961-1963)9.

\footnotetext{
${ }^{7}$ López, op. cit., 171-181; Amaral, op. cit., 194-195; Ranalletti, op. cit., 278; D a n i e 1 Mazzei, Bajo el poder de la caballería: el ejército argentino 1962-1973, Buenos Aires, Eudeba, 2012, 142.

8 López, op. cit., 41; Ranalletti, op. cit., 264; Mazzei, op. cit., 149.

9 John Nagl, Counterinsurgency lessons from Malaya and Vietnam: learning to eat soup with a knife, Westport, Praeger Publishers, 2002; Thomas Mockaitis, "Trends in American counterinsurgency", Paul Rich y Isabelle Duyvesteyn (eds.), The Routledge bandboook of insurgency and counterinsurgency, New York, Routledge, 2012; Daniel Marston, "The Vietnam War: the spectrum of conflict, 19541975”, Gregory Fremont-Barnes (ed.), A History of Counterinsurgency: from Cyprus to Afghanistan, 1955 to the 21st Century, Santa Barbara, Praeger, 2015. Los párrafos siguientes dedicados a la DSN son tributarios de esta bibliografía.
} 
A diferencia del abordaje galo, la DSN planteaba que el "comunismo internacional" basaba su estrategia en aprovechar las tensiones generadas por los procesos de modernización en los países del "Tercer Mundo". No obstante, se señalaba que los militantes comunistas orientaban sus acciones a lograr el derrocamiento de los gobiernos alineados con el bloque occidental por medio de técnicas de guerra de guerrillas, definidas de manera similar a la "guerra revolucionaria". Por consiguiente, se alertaba sobre la existencia de una amenaza global que basaba su actuación en evitar los peligros de un combate abierto con las fuerzas militares.

A partir de esta caracterización del enemigo, las FF.AA. debían encarar una estrategia integral no sólo a través de las armas-, priorizando la implementación de medidas preventivas a través de la llamada "acción cívica". De esta forma se conocía al uso de fuerzas militares locales en proyectos de utilidad para la población. En efecto, las áreas sobre las que se recomendaba actuar para contribuir al desarrollo económico y social incluían la educación, las obras públicas, el deporte, la agricultura, el transporte, las comunicaciones, la salud y la sanidad. Como señala Alicia Divinzenso, la "acción cívica" tenía por objetivo la construcción de una imagen positiva de las FF.AA. entre la población, promoviendo al mismo tiempo una representación determinada sobre el enemigo. A su vez, esta operación castrense se dirigía a fortalecer una estructura para el disciplinamiento y el control social en contextos de represión. Como muestra Divinzenso para el caso argentino, durante la primera mitad de los años sesenta las medidas de "acción cívica" se basaron en la intervención en zonas afectadas por desastres naturales. En relación con esto, las tareas realizadas incluyeron la evaluación de los daños, la evacuación y alojamiento de los afectados, la coordinación en la distribución y donación de alimentos y el restablecimiento de los servicios públicos. Junto a esto, las actividades promovidas durante todo el año se distribuían entre las áreas de educación, salud y deportes ${ }^{10}$.

Asimismo, producto de su actuación en la Guerra de Vietnam (1964-1975), a diferencia con la DGR -que se interesaba por el ambiente urbano- los teóricos estadounidenses de la DSN tenían una mayor preocupación por la lucha contra las guerrillas rurales. En relación con esto, se prescribía la creación de unidades de combate especiales de cincuenta hombres, con mando descentralizado y autonomía sobre el terreno. Por su parte, se retomaba el sistema francés de control de la población mediante la cuadriculación del territorio, aunque en este caso se lo aplicaba a un ambiente rural. Además, se recomendaba la ayuda de una fuerza de apoyo para asistir a las unidades de combate desde el aire por medio de helicópteros, advirtiendo que los armamentos y equipamientos pesados, así como la organización en regimientos, divisiones y cuerpos, incluidos los cuarteles generales, pasarían a ser elementos secundarios.

La colaboración con los países interesados en la asistencia estadounidenses se efectivizaba por medio de los llamados Programas de Asistencia Militar (PAM) -creados en 1952- y de la Foreing Assistance Act-de 1961-. En el caso de los primeros, el gobierno de los EE.UU. acordaba entregar armamentos y equipos a los países que tomaran parte en acciones contra las expresiones locales del comunismo, contribuir a la producción de insumos estratégicos para la industria bélica estadounidense y disminuir su comercio con los países del bloque enemigo. En relación con la Foreing Assistance Act, el objetivo era transferir los fondos provenientes de la "Alliance for Progress", un programa de cooperación económica, política y social para América Latina que estuvo vigente entre 1961 y 1970. Así, en el marco de un amplio programa de inversiones públicas y privadas que EE.UU. buscaba motorizar, se proyectaba elevar los estándares de la educación y la economía, con el objetivo de lograr reducir drásticamente los niveles de pobreza. A su vez, una parte de los fondos se destinarían a darles créditos y subsidios a las FF.AA. latinoamericanas para las compras de armamentos e insumos y para el entrenamiento de los oficiales en tácticas contrainsurgentes ${ }^{11}$.

10 Alicia Divinzenso, "La 'Acción Cívica' del Comando del II Cuerpo de Ejército. Un estudio de las relaciones cívico-militares en Rosario, 1960-1983”, Tesis de Maestría, Universidad Nacional de General Sarmiento, 2016, 31-57.

11 Mazzei, op. cit., 143-145 
El gobierno argentino inició las negociaciones para obtener un PAM a comienzos de la década del sesenta, concluyendo positivamente al año siguiente. Derivado de este convenio, los militares pudieron comprar equipos y armamentos en condiciones financieras favorables, iniciando la institucionalización del entrenamiento de oficiales argentinos en instituciones estadounidenses ${ }^{12}$. Así, la estrategia de EE.UU. -que buscaba convertir a las FF.AA. de los países latinoamericanos en garantes de la seguridad interna contra los adherentes locales al comunismo- encontró un terreno fértil en la Argentina. Para terminar, como se mostró anteriormente, desde fines de la década del cincuenta el Ejército había empezado a incorporar el abordaje antisubversivo de la seguridad interna mediante la DGR.

\section{Los aspectos desarrollistas de la Doctrina de Seguridad Nacional y su impacto local}

Como decíamos, en el contexto histórico político de la Guerra Fría, frente al constante temor a la proliferación de ideas y prácticas que cuestionaran el orden socioeconómico imperante, las potencias del occidente capitalista elaboraron teorías y políticas que apuntaron a realizar acciones preventivas.

En la concepción amplia de la "seguridad nacional" que postulaba la DSN existieron dos aspectos centrales: el político militar vinculado a la faceta represiva -al que hemos referido en el apartado anterior- y la dimensión social, económica y cultural ligada con otro tipo de intervención que buscaba el "desarrollo" de los países periféricos para evitar estallidos revolucionarios.

En este apartado nos detendremos en este último aspecto para analizar sus premisas, objetivos y prácticas, y cómo impactó en Argentina entre las décadas del cincuenta y setenta. El desarrollo económico, social y cultural del "Tercer Mundo", entonces, proporcionó el marco general de ideas a partir del cual se diseñó la intervención en América Latina promovida por los organismos internacionales y EE.UU. Las primeras experiencias de esta índole tuvieron lugar en la década del cincuenta en Asia y África en el marco del proceso de descolonización y de cuestionamientos a las potencias centrales y, poco tiempo después, intentaron implementarse en América Latina. ${ }^{13}$

El desarrollismo se vinculaba con el denominado "estructuralismo". Éste funcionó como un espacio de ideas, expertos y políticas que se entretejió en los organismos y se trató de aplicar en los países considerados subdesarrollados entre los años cincuenta y setenta. Suponía la existencia de un problema estructural de la periferia y, para resolverlo, le otorgaban importancia al desarrollo de la industria y del mercado interno, pero no a partir de un esquema proteccionista y nacionalista, sino focalizando en la centralidad de la tecnocracia, el mercado mundial y los capitales extranjeros. ${ }^{14}$ El objetivo era incentivar un proceso de modernización económica, social y política que emulara el proceso de desarrollo de los países centrales. En este sentido, también confluía con las teorías de la modernización y del crecimiento económico planificado en etapas, uno de cuyos exponentes era Walt Rostow, el asesor del presidente norteamericano Kennedy. Se consideraba que el fortalecimiento de la economía, el proceso de industrialización y las consecuentes transformaciones sociales cerrarían la pronunciada brecha entre ricos y pobres y producirían un incremento de las clases medias en los países en vías de desarrollo. Estas clases contribuirían a producir un mayor equilibrio por su supuesta inclinación hacia la democracia política. Esto, a su vez, contrarrestaría el comunismo y el "riesgo de revolución” al crear sociedades más afines al occidente capitalista. Aun así, esta teoría no se confirmaba en la realidad latinoamericana, ya que amplios sectores de las clases medias le otorgaron consenso a las dictaduras de la región. ${ }^{15}$

\footnotetext{
12 María Oliveira-Cézar, "Las raíces francesas de la guerra antisubversiva". Todo es Historia, 422, 2002, 28-29; Mazzei, op. cit., 146. 13 Carola Ravell y Maritza Izaguirre, Nuevo enfoque en el desarrollo de la comunidad, Buenos Aires, Editorial Humanitas, 1968.

14 Loris Zanatta, Historia de América Latina. De la Colonia al siglo XXI, Buenos Aires, Siglo Veintiuno Editores, 2012.

15 Tulio Halperin Donghi, Historia Contemporánea de América Latina, Buenos Aires, Alianza Editorial, 2011; Zanatta, op. cit.
} 
Desde mediados de la década de 1950, el objetivo del desarrollo se vehiculizó concretamente a partir de la difusión, por parte de Naciones Unidas y otros organismos internacionales, de un ideario y una propuesta que hacían énfasis en la noción de "asistencia técnica" procurada por las comisiones de expertos. Esto implicó la producción de un discurso técnico, científico y experto, y en apariencia desideologizado. En este sentido, además de la importancia que adquirían lo "técnico" y el "desarrollo", era evidente la presencia de algunos tópicos como "democracia" y "libertad" con los que pretendían promoverse formas de interrelación que buscaban ser opuestas a las acaecidas en el seno de los países del bloque soviético. En este marco comenzó a introducirse en los documentos oficiales de Naciones Unidas la importancia de promover el "desarrollo comunitario" en los países del tercer mundo. Según la Resolución 585/1955 de la ONU, las regiones económicamente más atrasadas podrían utilizar "la energía latente del pueblo en actividades orientadas a mejorar la situación de las comunidades a través de sus propios esfuerzos". ${ }^{16} \mathrm{Al}$ año siguiente, el organismo lanzó el documento Community development and services, en el que definió al desarrollo como "los procesos por los cuales los esfuerzos del pueblo se suman a los de su gobierno para mejorar económica, social y estructuralmente la comunidad y contribuir al progreso nacional". ${ }^{17}$

En este contexto político ideológico un suceso que fue central para comenzar a implementar estas ideas en América Latina fue la Revolución cubana de 1959. Como indicamos en el apartado anterior, este proceso revolucionario implicó el traslado y concreción material de la Guerra Fría en el continente americano y la inauguración de una nueva etapa de la misma en la región. ${ }^{18}$ Cuando pocos años después, en 1961, Kennedy asumió el poder en EE.UU. comenzó, entonces, a desarrollar el plan de ayuda económica llamado la Alianza Para el Progreso (ALPRO). Es importante considerar que, además de este plan de reformas, el Vaticano también comenzó, en simultáneo, a hacerse eco de las mismas ideas. En este sentido, algunas importantes encíclicas papales de los años sesenta, tales como Mater et Magistra (1962) y Pacem in Terris (1963) y Populorum Progressio (1967), focalizaban en la necesidad del "desarrollo de los pueblos".

En esas décadas, existían varias instituciones transnacionales que sostenían esas ideas desarrollistas que luego se sistematizaron en la ALPRO. Por un lado, la Comisión Económica para América Latina de la Organización de las Naciones Unidas (CEPAL-ONU), creada en 1951, cuyo secretario general fue Raúl Prebisch, quien recién tendría buenas relaciones con EE.UU. cuando Kennedy comenzó a preocuparse por los riesgos inherentes al subdesarrollo. Por otro, el Banco Mundial, que en esos años comenzó a considerar problemático el bajo nivel de ingresos de los sectores populares de los países del "tercer mundo". Además, tuvo bastante centralidad el Banco Interamericano de Desarrollo (BID) que pretendía aumentar la productividad de los países periféricos a partir de la mencionada "asistencia técnica". La creación de este banco fue reclamada bastante tiempo antes por los países latinoamericanos, pero recién se consumó en 1960.

Asimismo, un antecedente fundamental de ALPRO fue la Operación Panamericana propuesta por el presidente J. Kubitschek en 1958 a la Organización de Estados Americanos (OEA). La idea era estimular el desarrollo para la "defensa de occidente", brindando asistencia técnica para aumentar la productividad, estabilizar el mercado de productos primarios y conformar un mercado internacional. Esto fue percibido por EE.UU. como una amenaza a su poder en la región y estimuló también el impulso de ALPRO. ${ }^{19}$

Además de los organismos mencionados, el Consejo Interamericano Económico y Social (CIES) de la OEA se reunió en diferentes oportunidades con el fin de planear el desarrollo económico-social,

\footnotetext{
16 Citado en Karina Ramacciotti, "Políticas sanitarias, desarrollo y comunidad en la Argentina de los años sesenta", en Revista Ciencias de la Salud, vol. 12, no 1, 2014, pp. 89-109.

17 Ramaccioti, op. cit.

${ }^{18}$ Leandro Morgenfeld, "Desarrollismo, Alianza para el Progreso y Revolución Cubana. Frondizi, Kennedy y el Che en Punta del Este (1961-1962)", Ciclos en la historia, la economía y la sociedad, 20, 40, 2012, s/p.

19 Morgenfeld, op. cit.
} 
para lograr la integración de América Latina, resolver el problema de la vulnerabilidad de los mercados de productos básicos, reformar los sistemas tributarios, crear mercados de capitales y desarrollar instituciones financieras. En este contexto, en 1961, hubo una reunión del CIES en Punta del Este, en donde se conformó finalmente la ALPRO con los objetivos económicos de aumentar el ingreso per capita, mejorar la distribución del ingreso, diversificar la estructura económica para no depender del sector primario, acelerar el proceso e industrialización con énfasis en el desarrollo de bienes de capital, aumentar la productividad agrícola y promover la reforma agraria. También contemplaba los objetivos sociales de erradicar el analfabetismo, mejorar el sistema educativo, construir viviendas populares y aumentar la esperanza de vida al nacer. ${ }^{20}$

Además de las ideas generales que mencionamos, se le otorgaba mucha importancia a algunos tópicos propios de la época a la hora de pensar la implementación de las políticas públicas tales como la "modernización" en sentido amplio (estatal, económica, social, política, cultural), la "cooperación técnica" y la "planificación del desarrollo" (idea de demoler los obstáculos estructurales que impidieran el crecimiento). A su vez, tenían gran centralidad los tecnócratas y expertos que facilitarían la implementación del referido paquete de medidas.

En Argentina este clima de ideas y prácticas comenzó a impactar en los años de la dictadura "Revolución Libertadora" (1955-1958), cuando se abandonó la "tercera posición" del peronismo y el gobierno buscó estrechar relaciones exteriores con EE.UU. y con diferentes organismos internacionales. Los actores civiles y militares ligados al gobierno de facto de la "Libertadora" se autoproclamaron miembros del "mundo libre" que abogaba por la "paz", la "libertad" y la "democracia".

Como explica Alain Rouquié (1998), las recomendaciones del Plan Prebisch ${ }^{21}$ concernientes a las relaciones internacionales del país fueron bien recibidas por el gobierno provisional. ${ }^{22} \mathrm{El}$ equipo económico de Prebisch insistía en la necesidad de restablecer la confianza externa a fin de obtener ayuda financiera o una moratoria de la deuda y reanudar relaciones con los circuitos comerciales tradicionales. Obedeciendo a las recomendaciones imperativas de ese plan económico, las autoridades solicitaron el ingreso de la Argentina al Fondo Monetario Internacional y al Banco Mundial, y se firmaron los acuerdos de Bretton Woods. Además de estos vínculos con los organismos de crédito, los gobiernos de la "Libertadora", en diferentes oportunidades, recibieron las misiones de expertos en políticas sociales, culturales y educativas de las Naciones Unidas. ${ }^{23}$ Por ejemplo, en el caso de las políticas de vivienda, en noviembre de 1955, una comisión conformada por representantes de la CEPAL y del Centro Interamericano de Vivienda llegó al país con el objetivo de estudiar el problema y elevar un informe al organismo de asistencia técnica de la ONU que brindaría "tecnólogos, economistas y trabajadores sociales especialistas en el tema". ${ }^{24}$ Asimismo, el gobierno argentino directamente solicitaba este tipo de intervención experta a dicho organismo ${ }^{25}$ y este cambio de actitud era visto de manera auspiciosa por el director de Asistencia Técnica de la ONU quien afirmaba que "Argentina no había solicitado hasta ahora asistencia técnica". ${ }^{26}$ En ese marco, tuvieron lugar diversas visitas de altos funcionarios del organismo al

\footnotetext{
20 Orlando Aguirre, "La Alianza para el Progreso y la promoción en América Latina”, Revista Afuera, 9, 2010, s/p; Morgenfeld, op. cit.

${ }^{21}$ La propuesta de Prebisch consistía en una tecnificación agropecuaria comparable con la realizada en posguerra por EE.UU., Canadá y Australia. Su plan criticaba el déficit de las empresas públicas, los errores del IAPI, las regulaciones excesivas y el carácter regresivo del impuesto. Como contrapartida proponía volver al lucro industrial y/o comercial por su mayor eficiencia, descartando la inflación como medio. Alejandro Simonoff, La Argentina y el mundo frente al bicentenario de la Revolución de Mayo: Las relaciones exteriores argentinas desde la secesión de España hasta la actualidad, La Plata, EDULP, 2010.

22 Rouquié, Alain, Poder military sociedad política en la Argentina. Tomo II 1943/1973, Buenos Aires, Emecé, 1981.

23 Ramacciotti, op. cit.

${ }^{24}$ La Råón, 8/11/1955.

25 Comisión Económica para América Latina, Informe anual, (15 de mayo de 1956 - 29 de mayo de 1957), Documentos Oficiales, 24, Nueva York; La Razón, 12/1/1956; 4/5/1956.

${ }^{26}$ La Raðón, 22/3/1956.
} 
país. ${ }^{27}$ En 1956, cuando la ONU estaba creando un programa específico para Argentina, se afirmaba que el objetivo buscado era la "transferencia de los adelantos del progreso tecnológico de los países más avanzados a los países en proceso de desarrollo". La cooperación técnica era considerada un concepto revolucionario en materia de cooperación internacional, ${ }^{28}$ lo que mostraba, nuevamente, la novedad que se le atribuía a esta metodología de intervención.

Para lograr el cambio estructural deseado tenía que existir un cambio institucional. Esto implicaba otorgarle importancia al Estado y a su intervención en el proceso. En cuanto a las políticas económicas y sociales y su planificación, una agencia estatal que fue creada en la mayoría de los países latinoamericanos en el marco de la ALPRO fue el Consejo Nacional del Desarrollo (CONADE). ${ }^{29}$ En Argentina fue creado por Arturo Frondizi en 1961 con el objetivo de definir los objetivos del desarrollo económico a largo plazo, elaborar programas a corto y largo plazo, realizar inversiones, etc. En consonancia con los idearios transnacionales, el objetivo era la industrialización para construir una economía nacional menos vulnerable a las vicisitudes de mercado internacional y como eje de una sociedad moderna. Como indica Carlos Altamirano, en ese contexto se sostenía que el desarrollo era necesario, urgente e impostergable. ${ }^{30}$

El gobierno de facto presidido por Juan Carlos Onganía, quien asumió el poder tras el golpe de junio de 1966, profundizó el modelo de planificación y jerarquizó el CONADE. Esta dictadura también va a buscar modernizar el país en clave desarrollista. Con este fin, creó un Sistema Nacional de Planeamiento y Acción para el Desarrollo, al que se subordinaban los Consejos Nacional del Desarrollo y de Seguridad, lo que muestra la materialización institucional de los dos vectores de la DSN. Al sistema de planeamiento y a los consejos se subordinarían, a su vez, los ministerios del Poder Ejecutivo Nacional. En ese marco, en septiembre de 1966, se creó el Ministerio de Bienestar Social con el objetivo de llevar adelante el plan desarrollista. ${ }^{31}$ El gobierno de facto sostenía que este ministerio era una pieza central en la "nueva organización estatal revolucionaria" para llevar adelante el supuesto cambio de estructuras sociales, económicas y culturales. ${ }^{32}$ En el nuevo discurso, la política social no se asociaría ya a la "justicia social" o al mundo del trabajo formal, sino al "desarrollo social" o "bienestar social" más allá de la adscripción de clase. Este último concepto, según las voces oficiales, "puede representar la búsqueda de soluciones para problemas que afligen a toda comunidad moderna, pero sin la apelación a fórmulas teñidas por la demagogia". ${ }^{33}$ En este sentido, los destinatarios de estas políticas van a conceptualizarse como "pobladores", "vecinos" o "beneficiarios", y no ya como trabajadores. Dentro de este ministerio, la secretaría de Promoción y Asistencia de la Comunidad va a ser muy ilustrativa de estas transformaciones políticas y retóricas, porque se hizo eco de las recomendaciones internacionales sobre "desarrollo de la comunidad" surgidas de la ALPRO. ${ }^{34} \mathrm{El}$ comunitarismo implicaba desarrollar los

\footnotetext{
${ }^{27}$ La Razón, 1/4/1956; 15/2/1956.

28 La Razón, 12/2/1956.

${ }^{29}$ Aguirre, op. cit:; Anibal Jáuregui, “El CONADE: organización y resultados (1961-1971)”. Anuario IEHS, 29-30,2014-5, 141158.

30 Carlos Altamirano, Bajo el signo de las masas, 1943-1973, Buenos Aires, Ariel, 2001.

31 Ley 16956, Boletín Oficial, 27/09/1966. La Nación: 05/09/1966, 22/09/1966, 25/09/1966, 14/10/1966. Con respecto al ámbito de incumbencia del MBS, se afirmaba: "Su competencia radicará específicamente en la promoción y protección de los integrantes del cuerpo social sean individuos, familias o comunidades", La Nación, 22/09/1966. Ver también Gabriela Gomes, La politica social de los regimenes dictatoriales en Argentina y Chile: (1960-1970), La Plata: Universidad Nacional de La Plata. Facultad de Humanidades y Ciencias de la Educación; Buenos Aires: Universidad Nacional de General Sarmiento, 2016; Florencia Osuna “"El Ministerio de Onganía'. Un análisis de la conformación del Ministerio de Bienestar Social (1966-1970)”, Anuario de la Escuela de historia virtual, 11, 2017, pp. 69-91.

32 Boletín MBS, "El bienestar social como objetivo del desarrollo", 1969, p. 13.

33 La Nación, 29/09/1966.

34 Gabriela Gomes, "El Onganiato y los sectores populares: funcionarios, ideas y políticas de la Secretaría de Estado de Promoción y Asistencia a la Comunidad (1966-1970)", Anuario del Centro de Estudios Históricos "Prof. Carlos Segreti", 11, 2011, 279302; Osuna, La intervención social..., op. cit.; Guido Giorgi, "En los pliegues de la planificación del Onganiato: el comunitarismo como política estatal”, Anuario IEHS, 29-30, 2014/5, 159-175.
} 
barrios, localidades y municipios a partir de la "participación de la comunidad". Según el CIES, era la "técnica social de promoción del hombre". Suponía que las clases más bajas de los países periféricos tenían actitudes, hábitos y valores que trababan el desarrollo general y que erradicarlos era necesario para superar el atraso. Sin embargo, los sectores populares debían participar activamente en ese proceso. Es decir, no tenían que limitarse a cumplir roles pasivos y recibir ayuda del estado, sino promover ellos mismos el proceso de su superación. El hombre era considerado el responsable de su autodesarrollo. ${ }^{35}$ El secretario de Promoción y Asistencia de la Comunidad, Raúl Puigbó, sintetizaba esta idea a partir del principio de subsidiariedad del Estado: "El Estado debe planificar y conducir el proceso de desarrollo en los aspectos económicos, sociales y comunitarios, pero sin pretender asumir en forma exclusiva la ejecución de los planes y proyectos. Por el contrario, debe estimular las iniciativas de las personas y grupos organizados". ${ }^{36}$

Los expertos en "desarrollo de la comunidad", a partir de la aplicación de técnicas específicas, promoverían esa participación social que sacaría a los pobres de su pasividad para transformarse en los agentes del cambio. En este marco, los trabajadores sociales, los sociólogos, los politólogos y los psicólogos cumplieron un rol clave.

El propósito de "ir a lo local" implicaba el presunto fortalecimiento de los gobiernos de los niveles subnacionales y la descentralización. En los diagnósticos de los organismos, la causa de la centralización excesiva del diseño y ejecución de las políticas que caracterizaba a los países del "tercer mundo" se debía a la falta de personal calificado en los niveles provinciales y municipales, a la ausencia de líderes locales, al desinterés y apatía de los pobladores y a la carencia de recursos económicos y humanos..$^{37}$

Para finalizar, es importante considerar que más allá de algunos alcances puntuales, la ALPRO no fue exitosa en sus ambiciosos planes por diferentes razones, entre ellas, el asesinato de Kennedy y los escasos fondos para un proyecto de esas dimensiones. ${ }^{38}$ Pero es necesario tener en cuenta este marco para comprender algunas políticas públicas sociales, económicas, culturales y represivas de los gobiernos de los años sesenta y setenta en América Latina, en general, y en Argentina, en particular.

\section{Consideraciones finales}

Este artículo dio cuenta de un conjunto de discursos, actores y prácticas que se conformó en el marco de la Guerra Fría, y de su recepción en Argentina en el período 1955-1983. En este sentido, reconstruyó dos dimensiones transnacionales de la intervención en el "Tercer Mundo" por parte de las potencias occidentales que se condensaron en los conceptos interrelacionados de "seguridad" y "desarrollo" que buscaron detener el avance de ideas y proyectos presuntamente promovidos por el bloque soviético que atentaran contra el orden social, económico y político capitalista.

Así, el trabajo, por un lado, dio cuenta de las doctrinas, instituciones, organizaciones y actores más significativos de la Guerra Fría en el plano internacional que pugnaron por evitar y combatir esas alteraciones del orden, tales como la Doctrina de la Guerra Revolucionaria francesa, la Doctrina de la Seguridad Nacional norteamericana, la Alianza para el Progreso y los organismos internacionales (ONU, OEA, CEPAL, BID, entre otros). En relación con esto, demostró que sus diagnósticos, en términos generales, apuntaron a contrarrestar o prevenir la influencia del "comunismo" (más precisamente de las

\footnotetext{
35 Laura Golbert y Emilia Roca, De la Sociedad de Beneficencia a los Derechos Sociales, Buenos Aires, Ministerio de Trabajo, Empleo y Seguridad Social, 2010; Melisa Campana, "La intervención de la comunidad: el programa sanitarista para el trabajo social en la Argentina desarrollista", Tendencias \& Retos, 16, 2011, 127-43.

36 Crónica, 11/06/1967.

${ }^{37}$ Naciones Unidas, Actas de la Conferencia Internacional de Ministros Encargados de los Servicios de Bienestar Social, Nueva Cork, 1969 , p. 19 y p. 64.

38 Zanata, op. cit.
} 
prácticas contestatarias y revolucionarias), a partir del diseño específico de un amplio abanico de políticas: represivas, de defensa, de propaganda, económicas, sociales, culturales, entre otras.

Por otro lado, el artículo atendió al impacto y recepción local de este entramado complejo. Así, observó que, en todos los casos, se llevó a cabo una apropiación creativa del mismo que se conjugó con las particularidades de la Argentina de la época. En este marco, el peronismo fue conceptualizado como un enemigo interno a combatir en todos los planos: en las manifestaciones partidarias, militantes y sindicales concretas, pero también en su legado ideológico, político y estatal.

A su vez, al analizar la materialización de los vectores de la "seguridad" y el "desarrollo" en el plano nacional, el trabajo reconstruyó los dos ámbitos en los que impactó: las FF.AA. y el poder ejecutivo nacional. En este sentido, en las filas castrenses, las intervenciones a las que dio lugar, fueron represivas, pero, también, de acción cívica. Por su parte, en el PEN, supuso la restructuración de la institucionalidad estatal y la creación de nuevas agencias subordinadas a esos objetivos estratégicos.

Con el propósito de avanzar más allá de los aspectos vinculados a la DGR y a la DSN, para mediados de los años setenta, ¿cuáles eran los elementos distintivos de la doctrina de "guerra antisubversiva" del Ejército? En principio, todo saber contrainsurgente se caracteriza por tener un abordaje multidimensional de la preparación para una guerra interna, prestando atención a un grupo de factores políticos, sociales, económicos y culturales. No obstante, las diferentes experiencias antisubversivas que se han estudiado muestran que mientras en algunos casos es dominante un abordaje político (EE.UU. o Gran Bretaña, por ejemplo), en otros, por el contrario, se impone el militar (Alemania nazi o Francia, por citar algunas experiencias) ${ }^{39}$.

Si se la compara con las doctrinas francesa y estadounidense, el caso argentino exhibe un equilibrio de estos dos puntos de vista, a saber, el político y el militar. Asimismo, la mezcla de conceptos provenientes de estos modelos resultó en un abordaje contrainsurgente que atendía tanto a la "subversión" rural como a la urbana. Por consiguiente, para terminar, el conjunto de nociones de "guerra antisubversiva" que se condensaron a mediados de los años setenta, y que estuvieron en la matriz teórica y operativa del terrorismo de Estado, no conforman solamente una acumulación de ideas extraídas de doctrinas foráneas. También nos hablan de una apropiación creativa realizada por el Ejército argentino que derivó en el surgimiento de una doctrina contrainsurgente propia.

Finalmente, por todo lo expuesto, comprender acabadamente las características y el impacto en el país de la DSN es relevante, ya que esta doctrina de la Guerra Fría proporcionó los elementos de un paradigma a partir del cual se formularon las políticas públicas y represivas en la Argentina posperonista.

\section{Bibliografía}

1. Aguirre, Orlando. "La Alianza para el Progreso y la promoción en América Latina". Revista Afuera, $\mathrm{n}^{\circ} 9$ (2010), s/p. Recuperado de: http://www.revistaafuera.com/autores_detalle.php?id=94.

2. Altamirano, Carlos. Bajo el signo de las masas, 1943-1973. Buenos Aires: Ariel, 2001.

3. Amaral, Samuel. "Guerra revolucionaria: de Argelia a la Argentina, 1957-1962". Investigaciones y Ensayos, $\mathrm{n}^{\circ} 48$ (1998).

Disponible en: https://www.academia.edu/7759928/Samuel_Amaral_Guerra_revolucionaria_de_Argelia_a_1 a_Argentina_1957-1962_.

${ }^{39} \mathrm{Nagl}$, Counterinsurgency lessons...; Marnia Lazreg, Torture and the Twilight of Empire: From Algiers to Baghdad (New Jersey: Princeton University Press, 2008). 
4. Calandra, Benedetta. y Franco, Marina. "Desafíos y límites para una nueva mirada de las relaciones interamericanas". En La Guerra fría cultural en América Latina, compilado por Calandra, Benedetta y Franco, Marina. Buenos Aires: Biblos, 2012.

5. Campana, Melisa. "La intervención de la comunidad: el programa sanitarista para el trabajo social en la Argentina desarrollista". Tendencias \& Retos, no 16 (2011), pp. 127-43. Disponible en: http://www.memoria.fahce.unlp. edu.ar/libros/pm.483/pm.483.pdf

6. Divinzenso, Alicia. "La 'Acción Cívica' del Comando del II Cuerpo de Ejército. Un estudio de las relaciones cívico-militares en Rosario, 1960-1983”. Tesis de Maestría, Universidad Nacional de General Sarmiento, 2016a.

7. Fremont-Barnes, Gregory, compilador. A History of Counterinsurgency: from Cyprus to Afghanistan, 1955 to the 21st Century. Santa Barbara: Praeger, 2015, Volumen 2.

8. Giorgi, Guido (2014/5). "En los pliegues de la planificación del Onganiato: el comunitarismo como política estatal”. Anuario IEHS, n 29-30 (2014/5), pp. 159-175.

9. Golbert, Laura y Roca, Emilia. De la Sociedad de Beneficencia a los Derechos Sociales. Buenos Aires: Ministerio de Trabajo, Empleo y Seguridad Social, 2010.

10. Gomes, Gabriela. "El Onganiato y los sectores populares: funcionarios, ideas y políticas de la Secretaría de Estado de Promoción y Asistencia a la Comunidad (1966-1970)". Anuario del Centro de Estudios Históricos "Prof. Carlos Segreti", n 11 (2011), pp. 279-302.

11. Gomes, Gabriela. La politica social de los regimenes dictatoriales en Argentina y Chile: (1960-1970). La Plata: Universidad Nacional de La Plata. Facultad de Humanidades y Ciencias de la Educación; Buenos Aires: Universidad Nacional de General Sarmiento, 2016.

12. Halperin Donghi, Tulio. Historia Contemporánea de América Latina. Buenos Aires: Alianza Editorial, 2011.

13. Jáuregui, Anibal. "El CONADE: organización y resultados (1961-1971)”. Anuario IEHS, n²9$30(2014 / 5)$, pp. 141-158.

14. Kaplan, Oscar, Diccionario Militar. Buenos Aires: Biblioteca del Suboficial, 1944.

15. Lazreg, Marnia. Torture and the Twilight of Empire: From Algiers to Baghdad. New Jersey : Princeton University Press, 2008.

16. López, Ernesto. Seguridad Nacional y sedición militar. Buenos Aires: Legasa, 1987.

17. Marston, Daniel. "The Vietnam War: the spectrum of conflict, 1954-1975". En A History of Counterinsurgency: from Cyprus to Afghanistan, 1955 to the 21st Century, compilado por FremontBarnes, Gregory. Santa Barbara: Praeger, 2015, Volumen 2. Santa Barbara: Praeger, 2015, Volumen 2.

18. Mazzei, Daniel. "La misión militar francesa en la Escuela Superior de Guerra y los orígenes de la Guerra Sucia, 1957-1961". Revista de Ciencias Sociales, n 13 (2002), pp. 105-137.

19. Mazzei, Daniel. Bajo el poder de la caballería: el ejército argentino 1962-1973. Buenos Aires: Eudeba, 2012.

20. Mockaitis, Thomas. "Trends in American counterinsurgency". En The Routledge handboook of insurgency and counterinsurgency, compilado por Rich, P. y Duyvesteyn, I. New York: Routledge, 2012.

21. Morgenfeld, Leandro. "Desarrollismo, Alianza para el Progreso y Revolución Cubana. Frondizi, Kennedy y el Che en Punta del Este (1961-1962)". Ciclos en la historia, la economía y la sociedad, $\mathrm{n}^{\circ}$ 20 (40) (2012), s/p. Recuperado de:

22. http://www.scielo.org.ar/scielo.php?script=sci_arttext\&pid=S1851-37352012000200001

23. Nagl, John. Counterinsurgency lessons from Malaya and Vietnam: learning to eat soup with a knife. Westport: Praeger Publishers, 2002.

24. Novaro, Marcos y Palermo, Vicente. La dictadura militar 1976-1983: del golpe de Estado a la restauración democrática. Buenos Aires: Paidós, 2006. 
25. Oliveira-Cézar, María. "Las raíces francesas de la guerra antisubversiva". Todo es Historia, n 422 (2002), pp. 24-34.

26. Osuna, María Florencia. La intervención social del Estado. El Ministerio de Bienestar Social entre dos dictaduras (Argentina, 1966-1983). Rosario: Prohistoria, 2017.

27. Osuna, María. Florencia. “'El Ministerio de Onganía'. Un análisis de la conformación del Ministerio de Bienestar Social (1966-1970)". Anuario de la Escuela de historia virtual, n 11 (2017a), pp. 69-91.

28. Pontoriero, Esteban. "La seguridad interna como 'teatro de guerra': estado de excepción y contrainsurgencia en la Argentina (1955-1976)". Tesis de Doctorado. Instituto de Altos Estudios Sociales, Universidad Nacional de San Martín, 2017.

29. Ramacciotti, Karina. (2014). "Políticas sanitarias, desarrollo y comunidad en la Argentina de los años sesenta". Revista Ciencias de la Salud, n¹ (2014), 89-109.

30. Ranalletti, Mario. "Una aproximación a los fundamentos del terrorismo de Estado en Argentina: la recepción de la noción de 'guerra revolucionaria' en el ámbito castrense local (1954-1962)". Anuario del Centro de Estudios Históricos "Prof. Carlos S. A. Segreti", nº 11 (2011). Disponible en: https://dialnet.unirioja.es/servlet/articulo?codigo $=4775072$.

31. Ravell, Carola e Izaguirre, Maritza. Nuevo enfoque en el desarrollo de la comunidad. Buenos Aires: Editorial Humanitas, 1968.

32. Robin, Marie-Monique. Escuadrones de la muerte: la escuela francesa. Buenos Aires: Sudamericana, 2005.

33. Rouquié, Alain. Poder militar y sociedad política en la Argentina. Tomo II 1943/1973. Buenos Aires: Emecé, 1981.

34. Simonoff, Alejandro. La Argentina y el mundo frente al bicentenario de la Revolución de Mayo: Las relaciones exteriores argentinas desde la secesión de España hasta la actualidad. La Plata: EDULP, 2010.

35. Tcach, César. "Golpes, proscripciones y partidos políticos”. En Nueva historia argentina: Violencia, proscripción y autoritarismo 1955-1976, compilado por Daniel James. Buenos Aires: Sudamericana, 2003, volumen 9.

36. Zanatta, Loris. Historia de América Latina. De la Colonia al siglo XXI. Buenos Aires: Siglo Veintiuno Editores, 2012. 